\title{
The Construction of Application-oriented Teaching Staff in the Context of the Transformation and Development of Independent Colleges
}

\author{
Fan Yanhua ${ }^{1}$, Wang Lijun ${ }^{2}$ \\ ${ }^{1}$ Department of Human Resource Management, Jiangsu University, Zhenjiang, China \\ ${ }^{2}$ Department of Student Affairs, Jiangsu University Jingiiang College, Zhenjiang, China \\ Email address: \\ 2716138604@qq.com (Fan Yanhua),534508963@qq.com (Wang Lijun)
}

To cite this article:

Fan Yanhua, Wang Lijun. The Construction of Application-oriented Teaching Staff in the Context of the Transformation and Development of Independent Colleges. Science Journal of Education. Vol. 7, No. 4, 2019, pp. 95-100. doi: 10.11648/j.sjedu.20190704.14

Received: July 21, 2019; Accepted: September 12, 2019; Published: September 26, 2019

\begin{abstract}
As an important supporting force of national competitiveness, higher education must actively adapt to economic and social changes and strive to enhance the competitiveness of education [1]. Up to now, both government departments and all walks of life have made it clear that the transformation to application-oriented colleges should become an important direction of the transformation and development of independent colleges. Independent colleges should seize the opportunity of transformation and development, clarify the orientation of running schools, and strengthen the training characteristics of skilled and applied talents. The construction level of application-oriented teachers determines the level of school running and the healthy and sustainable development of the transformation development. This paper analyzes the bottlenecks in the transformation and development of independent colleges, current situation of the teaching staff and the difficulties encountered in the transformation, and then promotes the construction of applied teachers from three aspects: government policy support, Participation of social forces, optimization of the structure of school teachers, and reconstruction of teachers' self-identity.
\end{abstract}

Keywords: Transformation and Development, Applied Pattern, Faculty

\section{Introduction}

The 19th national congress of the communist party of China (CPC) proposed the goal of deepening supply-side structural reform. As an important part of economic and social development, higher education plays an important supporting role. As an important part of higher education, independent colleges successfully transform to application-oriented development, which is not only a process in which the popularization of higher education and the transformation and development of local economy and society run into each other, but also the key to solve the problem of structural mismatch between supply and demand of college graduates. "The decision of the state council on accelerating the development of modern vocational education" points out that "when independent colleges are transferred to independent institutions of higher learning, they should be encouraged to position themselves as institutions of higher learning of applied technology", which further points out the direction for the transformation and development of independent colleges. In the process of transformation from independent colleges to application-oriented colleges, new reference systems have been endowed with new structural functions in terms of personnel training objectives, discipline and specialty orientation, faculty construction and school-running characteristics. The bottleneck and key to promote the transformation lies in the construction of application-oriented teachers [2]. Therefore, the construction of teachers' talent team is the first problem to be considered and solved in the transformation process.

\subsection{Connotation of Application-oriented Teachers}

In recent years, independent college is an ordinary institution of higher learning developing towards application-oriented transformation based on the change of society's demand for application-oriented talents. Its orientation and development goal is to train front-line applied talents, who can directly serve the local economic 
development after graduation, such as front-line logistics, nurses, engineers, etc. Application-oriented teachers are different from academic teachers in terms of knowledge quality, ability structure, teaching concept and teaching organization mode [3]. They should be able to possess comprehensive skills needed to train front-line application-oriented talents.

\subsection{Characteristics of Application-oriented Teachers}

Application-oriented teachers should be the combination of "double teachers" and "double abilities". "Double division" refers to both teacher qualification and engineer qualification. "Double energy" refers to both teaching and practice. In terms of individual quality, teachers should be able to combine theory with practical experience. In terms of group quality, some teachers have good theoretical level, while others have strong practical ability and applied research and development ability [4]. They should complement each other.

\section{Method}

At present, the development of independent colleges mostly depends on the parent schools, and they cannot make rapid adjustment in personnel training, policy guidance and other aspects, or they are not equipped with sufficient conditions to make rapid adjustment to meet the needs of The Times. The factors restricting the construction of application-oriented teaching staff mainly include the following aspects.

\subsection{The Transformation Time Span Is Large}

The transformation and development of independent colleges need a long process of exploration and adjustment. At present, there is a certain disconnect between the goal of talent cultivation and teaching plan of the school and the demand of the industry and the development of economy and society. In order to further guide the construction and training of teaching staff, it is necessary to fully investigate the standards of social demand for talents, develop professional courses that meet the needs of the industry and enterprises, and optimize the training programs that take the training of application-oriented talents as the main objective. The change of training objectives of transformational talents requires teachers to transform to application-oriented teaching [5]. It is a complicated project to clarify the demand of different professions for different talents, especially the transformation and development requirements of the society on the industry, which also brings certain influence to the finalization of the talent training program.

\subsection{The Assessment and Evaluation System Is Not Sound Enough}

Traditional evaluation system focusing on the theoretical teaching and the evaluation of academic achievements, neglected the evaluation of practice teaching [6], especially in the title promotion, performance appraisal, etc, too much emphasis on to investigate the workload and academic achievements, this is a certain level of applied for the construction of teaching staff to form the wrong guiding role, the enthusiasm of teachers to applied in the transformation. After the transformation, the professional title evaluation was mainly based on the former evaluation system, but the school made you focus on practice in teaching, which is also a big contradiction and difficulty [7].

\subsection{Insufficient Social Support}

In a sense, the construction of application-oriented teaching staff is inseparable from the support of all walks of life, especially enterprises and industries. In order to promote the construction of application-oriented teaching staff, the school must establish a good cooperative relationship with the industry and enterprises, and achieve mutual benefits and mutual benefits. However, at present, the channels for independent colleges to obtain resource support or industrial enterprises are not smooth enough. In addition, independent colleges are in the early stage of transformation. In the process of industry and education integration, due to the game of incomplete information, industrial enterprises are cautious [8].

\subsection{The Total Number of Teachers Is Not Enough}

If the construction of application-oriented teaching staff is to be realized rapidly, it will inevitably bring some difficulties to the teaching arrangement if teachers of various disciplines and majors are sent to practice learning in industrial enterprises in batches. However, the current situation is that there are not enough full-time teachers in independent colleges, which to some extent restricts the process of sending teachers to practice learning in enterprises. In addition, due to the limitation of funds, the number of teachers assigned to foreign countries and the duration of part-time study will be limited to some extent. In many newly added majors, the teaching staff has grown from nothing, making it difficult for students to receive reasonable and comprehensive teaching guidance [9].

\section{Result}

\subsection{The Main Body of Full-time Teachers Is Theoretical Teachers}

Independent institute developed in colleges and universities as a special historical period, influenced by factors such as education level and historical mission, it's inevitable have the basic characteristics of the "dependent", most of the target type for the traditional teaching undergraduate course colleges and universities, the main body of full-time teachers are graduates of colleges and universities, from other colleges and universities to, enterprise to few, such as the percentage of teachers' discipline structure, practice experience, industry background remains to be further improved. The reasons for this state of affairs are manifold. For example, in terms of personnel recruitment, although independent colleges have certain right to recruit teachers, they must meet the requirements of basic education and degree stipulated by the council, which makes it difficult for those professionals with 
insufficient education but rich practical experience to enter the society. However, the current salary and treatment of independent colleges do not have the advantage of competitive enterprises with good benefits, so it is difficult to attract talents with high education background and rich practical experience. Policy encouragement: the current policy guidance lacks positioning guarantee. In the evaluation index system of independent colleges by higher authorities, independent colleges must attach importance to the introduction of theoretical teachers to some extent.

\subsection{Imbalance of Faculty Structure}

Due to the short development history of independent colleges, the overall strength of the teaching staff is not strong enough and there is a lack of high-level talents [2]. According to the relevant research and survey, among the independent colleges' own teachers, nearly $70 \%$ are directly employed by fresh graduates, more than $60 \%$ are young (under 35 years old), and nearly $80 \%$ are with intermediate or lower titles. The structure of the teaching team presents different degrees of imbalance [10]. Lack of teaching experience, enterprises part-time training opportunities, weak practical teaching ability, production, learning and research out of touch, which to some extent restricts the construction of application-oriented teachers. This situation is directly related to the large number of supplements of the concentration of the independent college's teaching staff in recent years. The growth of the teaching staff is slow, and it is difficult to realize the rationalization of the structure in a short time. On the other hand, compared with public universities, independent colleges have no advantages in attracting talents in terms of development prospects, scientific research conditions, salary and remuneration.

\section{Discussion}

Schulz, the father of the concept of human capital, emphasized in his book on human capital investment that human capital has a greater role than material capital. He pointed out: "human capital is knowledge and skills... We call this capital human, because it has become a part of man, and because it can bring satisfaction or income, so it is called capital. From the perspective of human capital theory, teachers are the core components of human resources in independent colleges in the process of transformation and development. To build a team of practical application-oriented teachers is the primary task of characteristic development and talent cultivation in the process of transforming independent colleges into application-oriented colleges, and it is also the basic way to realize the increment of teachers' human capital.

According to the statistics of cnt. cn, in the past three years, there have been nearly 300 studies on "application-oriented teacher team construction". Based on the analysis of the latest research, the proposed measures mainly focus on the following two points: first, "the cultivation path of application-oriented teacher team requires the policy support of the government and society to escort it. For example, Shi lanyue explored the way to train "double-qualified" teachers in her research [11]. Sun Qingling etc. [12] proposed that school-enterprise co-education and training of teachers should be carried out. Tian Jing pointed out in her research that the transformation of teachers should be realized through school-enterprise cooperation and integration of industry and education [13]. Lack of the university's own resources mining, such as: through targeted training of graduates for enterprises to achieve the construction of faculty, alumni resources mining. Second, in the internal training link, the professional title appraisal and employment system reform is widely adopted, but the intensity is not big enough, should dilute the basic research, more to the achievement transformation research and the technical transformation research to do the guidance.

\subsection{Macro Level: The Government Improves the Policy System and Highlights the Practical Ability of Teachers}

Improve the mechanism: promote the construction of application-oriented teachers

For the problems existing in the transformation process, the government should further strengthen the system design, improve the system and mechanism, give special support to the construction of teachers' team in policy, and improve the practical application ability of teachers. Guide and break the traditional mode of thinking and school-running mode, change the "heavy science, light technology, heavy theory, light practice" thoughts, establish and improve the "double double" teachers' qualification authentication system and professional titles evaluation system, at the same time break university-enterprise cooperation and integration in the process of production and education policy barriers, create good development environment for applied teachers team construction.

Build platform: build a platform for "school-enterprise" and "school-school" cooperative teacher training

The government should promote the top-level design for industry experts to enter universities. Since 2010, five departments including the organization department of Jiangsu provincial party committee, provincial department of education, provincial department of science and technology, provincial department of human resources and social security, and provincial department of finance have taken the lead in selecting and hiring industry professors, "introducing enterprises to universities", and promoting cooperation between enterprises and universities [2]. From the perspective of practice, the school should actively seek social resources, establish a profit-driven mechanism, find a balance between the interests of both sides, mobilize the enthusiasm of the cooperation between the school and the enterprise, establish a teacher training base, allow teachers to get involved in front-line practice, and improve professional practice ability and industrial service ability. Actively seek cooperation between other colleges and universities, and promote resource sharing by means of teacher exchange and temporary study.

Innovation mode: diversified talent introduction mode In order to build a scientific and application-oriented 
teaching team, it is necessary to innovate the talent introduction mode and establish a flexible talent introduction mechanism on the basis of traditional personnel recruitment [2]. Will be part-time employment, external employment, retirement and other diverse ways of introduction combined. In the talent introduction plan, it focuses on the inclination of the introduction of applied talents. In accordance with the concept of "all at once, mutual benefit and resource sharing", it cooperates with production and management experts of industrial enterprises in flexible ways such as short-term employment and expert consultant to build a diversified team of teachers. In particular, it is necessary to establish long-term employment relations with social enterprise talents with strong ability [14]. Only when the age structure, professional title structure, discipline structure and proportion of applied talents of the teaching staff form a relatively stable and scientific connection mode, can form a benign development pattern of "bringing the weak with the strong" and "bringing the new with the old".

\subsection{Middle Level: Schools Seize the Transition and Development Node to Optimize the Functional Structure of Teachers}

Teacher recruitment: pay attention to the combination of "internal training" and "external introduction"

In view of the current status of independent college teaching staff, the only way to promote the construction of application-oriented teaching staff is to adopt internal training, and to cite the model of "double-qualified" teachers [15]. The focus of this model is to promote the transformation of existing teachers from traditional academic to applied under the guidance and encouragement of school policies. To make this point clear is helpful for us to grasp the focus and direction of the construction of teaching staff, and further promote the external recruitment of "double-qualified" teachers when the application-oriented school-running features are fully available.

Teacher training: pay attention to the combination of "part-time training" and "school teaching"

In the past, the training of teachers was mainly focused on the basic theory of education and teaching, basic quality and professional knowledge content, lacking of professional practice training. On the one hand, the school should take the initiative to go out, contact the practice training base, establish a long-term cooperative relationship, in line with the principle of "dispatching professional teachers as needed and putting what they have learned into practice", and select professional teachers to participate in the front-line practice of production and management in industrial enterprises in batches, in a planned and organized way [16]. Professional teachers into a line, is not only beneficial to its own theory combined with production practice, promote professional practice ability, is more advantageous to learn through practice experience in production technology, management, enterprise of knowledge structure and talented person's demand, better guide the teaching goal, improve the effect of the practice teaching and theories teaching. On the other hand, in the training link of the tutorial system for young teachers, explore the professional tutorial system mode, introduce experts from the production line of enterprises and backbone teachers with theoretical teaching experience in universities to jointly undertake the training of the theoretical and practical links for young teachers.

Teacher evaluation: pay attention to the combination of "academic achievements" and "practical ability"

In order to realize the stimulating and guiding effect of the assessment system on the transformation of teachers into application-oriented ones, and to fully mobilize the enthusiasm and initiative of the transformation of teachers, it is necessary to change the traditional main indicators of teaching workload and scientific research achievements. It reflects the policy encouragement and system restriction to teachers' practical teaching ability level and experimental training teaching quality. For example, teachers should realize the comprehensive evaluation of their own practical learning, practical teaching level and workload in the performance appraisal. In the work of professional title review, post appointment, and selection of backbone teachers, it is necessary to specify the cycle of practice practice, evaluation of practical teaching and other contents, and encourage teachers to take the initiative to transform themselves through policy guidance. Establish reasonable standards for teacher identification and standardize practical ability, training time limit and skill level [17].

\subsection{Micro Level: Teachers Reconstruct Their Self-identity and Promote the Improvement of Practical Teaching Ability}

Changing concept: to increase the awareness of application-oriented education and teaching

Marx believed that consciousness has the function of guiding and controlling human behavior and physiological activities. Therefore, to promote the construction of application-oriented teachers, teachers should form a strong sense of identity. Teachers should according to the transformation of the development of the demand of school-running orientation, discipline construction, and the society, industry development prospects, combined with the regional economic development, break the traditional ideas of theory teaching, in the theoretical teaching at the same time should also pay attention to improve the practice teaching of thinking, efforts to improve the teaching concept into practice, the ability of teaching achievements.

Focus on practice: promote the reform of application-oriented teaching model

The improvement of teachers' practical teaching ability requires teachers to cultivate and test constantly in the process of teaching practice. Application-oriented teaching requires teachers to combine theoretical knowledge with practical operation flexibly so that students can enhance practical professional skills on the basis of mastering theoretical knowledge. In the revision of the teaching plan, the theoretical class and practical class hours are allocated reasonably, and the former model of absolute dominance of theoretical class 
hours should be abandoned. Let students go out of the campus, out of the classroom, the classroom teaching into the society to practice, and industry, enterprise requirements, guide students to apply theory to practice in the practice process, find the problem back to the classroom to solve, for the school enterprise production, learning and research to establish a bond, can not only solve the problem of insufficient teachers, but also promote the process of application-oriented personnel training.

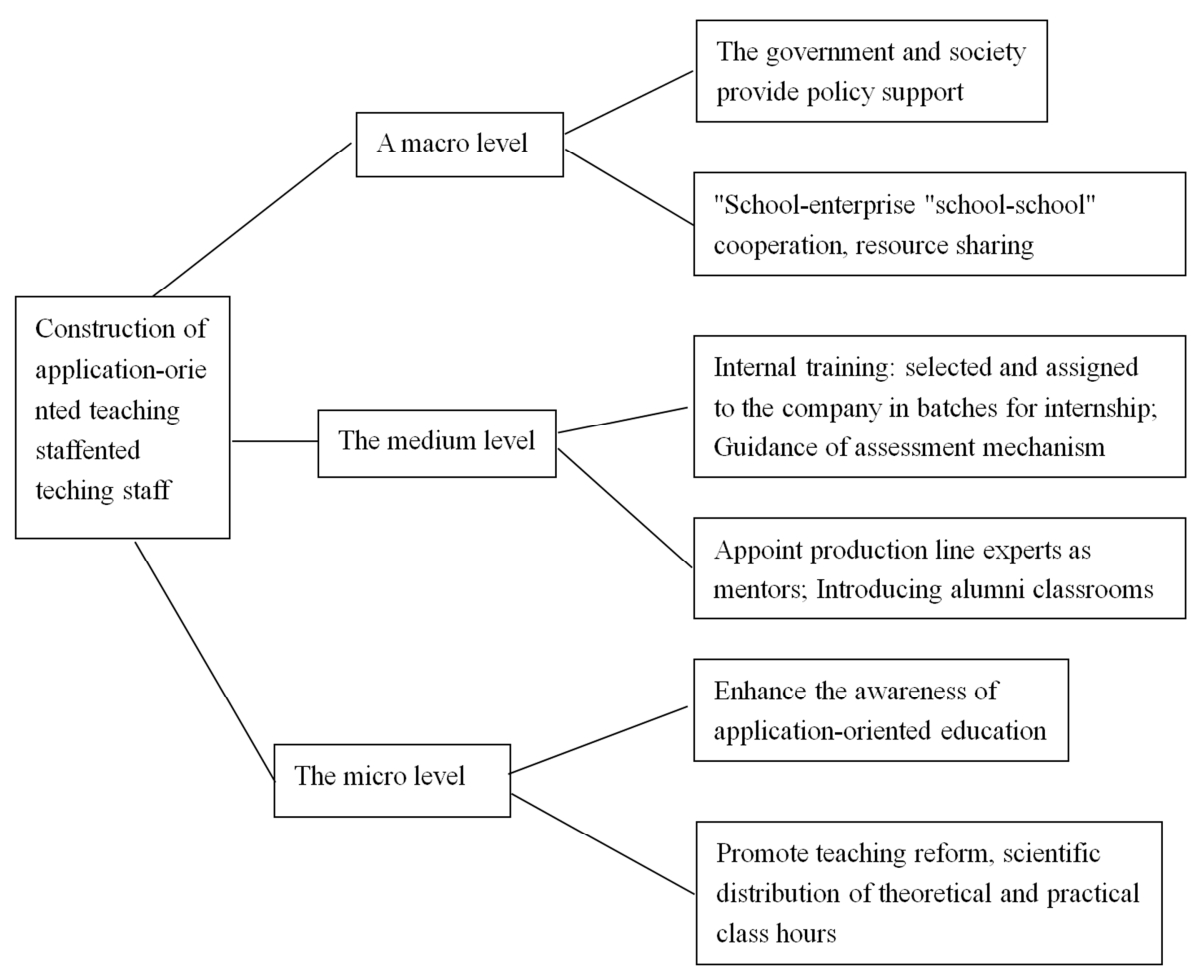

Figure 1. The realization path of the construction of application-oriented teaching staff.

\section{Conclusion}

Considering the current situation of the teaching staff, the collection of several problems is still the main bottleneck that restricts the development of independent colleges to application-oriented transformation. However, the construction of application-oriented teaching staff cannot be accomplished overnight, and needs diversified efforts from the society, the government and schools. We try to find out the difficulties and contradictions in the construction of application-oriented teaching staff, so as to explore effective implementation paths.

\subsection{Government Policy Support}

Government departments should lead the establishment of state-level teaching and training bases, establish cooperative relations between enterprises and teaching and training bases, and provide front-line production and internship training for teachers by relying on the practical ability advantages of senior technical personnel of enterprises. The government can also use tax preferential policies or special subsidies to stimulate enterprises' active participation [10].

\subsection{Subject Participation at the Social Level}

Social enterprises can cooperate with schools to carry out targeted training based on employment standards, so as to obtain support from enterprises in the training of teachers. And actively communicate with each other in practical training expenses, management assessment and other aspects to form feasible plans.

\subsection{Institutional Guarantee at the School Level}

The school should formulate a strict evaluation and assessment system for teachers who practice in enterprises, and provide support in terms of workload transformation and salary guarantee. We should draw closer to the applied teachers in colleges and universities through the separation of evaluation and recruitment and the classified management and assessment [18], so as to improve the initiative and enthusiasm of teachers to participate in training in the production line.

Along with the development process of the transformation of local colleges and universities, in the construction of teachers team encountered difficulties and bottlenecks become increasingly obvious, through to the research of other universities, combined with the present situation of teaching staff, has carried on the related research and gives the Suggestions, some have started to practice in the author's colleges and universities, such as the title appraisal and separation and increase the professional practice of evaluation, etc.

No matter which method is adopted to promote the construction of application-oriented teachers, we should 
always adhere to the practical and applied orientation, and serve the local economy. In addition, process awareness should also be emphasized [19]. No matter in Germany, Switzerland or other countries, the development of application-oriented teacher training cannot be achieved overnight. We must have a tolerant attitude and have the awareness that only years of development can achieve the goal.

\section{Fund Project}

Jiangsu university philosophy and social science foundation project: study on the effectiveness of ideological and political theory course in independent colleges from the perspective of socialist core value system (2017SJB2171).

\section{References}

[1] Lu Xianliang. Construction of faculty in application-oriented undergraduate universities under the background of new engineering [J]. Education and career, 2019 (5).

[2] Zhang Yidan, Wang Xiong, Han Yao. Construction of application-oriented teaching staff: key path of transformation of local undergraduate universities [J]. Consumer guide, 2016 (7).

[3] Li Decai. Problems and countermeasures in the construction of teachers in application-oriented universities [J]. Research on application-oriented higher education, 2018 (3): 30-34.

[4] Li Xiang, Guo Qi. Research on orientation and training mode of application-oriented teachers in newly established undergraduate universities [J]. Law and society, 2009 (8): 276.

[5] Chen Ligan. Exploration on the construction of application-oriented teaching staff in newly built undergraduate universities in the period of transformation and development [J]. Journal of chifeng university (natural science edition), 2019 (6).

[6] Wen Panya. New undergraduate universities should strengthen the construction of "double-qualified" teaching staff $[\mathrm{J}]$. China higher education, 2017 (16).

[7] Wu Hongfu, Fan Chunmei. Action barriers of teachers in technology-oriented universities from the perspective of transformation and development -- based on interviews with 30 teachers in X college [J]. Vocational education BBS, 2018 (1): 84 .
[8] Chang Dongmei. Problems and ideas on the construction of vocational education teachers from the perspective of coordination and innovation [J]. Education and career, 2019 (6).

[9] Zhang Yaping. Analysis on existing problems and countermeasures in the construction of teachers' teams in local colleges and universities [J]. New west region (theoretical edition), 2016 (20).

[10] Liu Jingjing, Li Mengqing. Reflection and promotion of faculty construction in applied technology university [J]. Education and career, 2019 (5).

[11] Shi Lanyue. Exploration on ways to strengthen the construction of "double-qualified" teachers in application-oriented undergraduate colleges and universities in henan province $[\mathrm{J}]$. Journal of henan college of finance and taxation, 2019 (3) 88-90.

[12] Sun Qingling, Wang Yifei. How to build "double teachers" [N]. China youth daily, 2019 (006).

[13] Tian Jing. Ecological observation of teacher development in the context of local university transformation $[\mathrm{J}]$. Exploration of higher education, 2019 (1) 124-128.

[14] Fu Dayou. New construction period, application-oriented, local: key words for the transformation and development of new undergraduate institutions [J]. China higher education, 2016 (22).

[15] $\mathrm{Fu}$ Bajun. On the endogenous model of teaching staff construction in application-oriented universities [J]. Zhejiang social sciences, 2017 (6).

[16] Liu Jingfei. Strategy research on strengthening the construction of practical teaching faculty in application-oriented undergraduate institutions [J]. Journal of hubei university of science and technology, 2015 (12) 91-93.

[17] Wei Aiping. Practical difficulties and solutions for the construction of teachers in application-oriented colleges and universities from the perspective of human capital theory $[\mathrm{J}]$. Education and career, 2019 (5) 76-80.

[18] Huang Fengshan. Analysis on the construction and development of application-oriented teachers [J]. Education modernization, 2018 (16).

[19] Wang Baoxi. Ecological observation of teachers' development in the context of local university transformation $[\mathrm{N}]$. China science journal, 2019 (007). 